\title{
Electrochemical Oxygen Reduction Reaction Performance of Water Hyacinth Derived Porous Non-precious Electrocatalyst in Alkaline Media
}

\author{
Krlangsak Ketpang ${ }^{1,4+}$, Jenkamol Prathum ${ }^{1}$, Pummarut Juprasat ${ }^{1}$, Wararak Junla ${ }^{1}$, Kittisak Wichianwat ${ }^{1}$, Aptchat Saejio ${ }^{2}$, \\ Chedthawut Poompipatpong ${ }^{3,4}$, and Noppavan Chamunpanichs, \\ ${ }^{1}$ Faculty of Science, Encrgy and Environment, King Monglout' = University of Technology North Bangkok, Rayong Campus, Rayong, \\ Thailand \\ 'Faculty of Engincering and Technology, King Monglut's University of Technology North Banglok, Rayong Campus, Rayong, \\ Thailand \\ 'Automotive Eco-Energy and Industrial Product Standard Rescarch Center, Scicnce and Technology Rescarch Institute, King \\ Mongkut's University of Technology North Bangkok, Rayong, Thailand \\ 'College of Industrial Technology, King Mongkut's University of Technology North Banglook, Bangleok, Thailand \\ 'Integrated Nanoccienee Reacarch Center, Scicnee and Technology Reacarch Institute, King Monglwt'a University of Technology \\ North Bangkok, Bangkok, Thailand \\ 'Department of Industrial Chemistry, Faculty of Applied Scicnec, King Mongkut's University of Technology North Bangkok, \\ Banglrole, Thailand
}

\begin{abstract}
This rescarch studied the possibility of converting water hyacinth biomass into the porous nonprecious oxygen reduction reaction (ORR) clectrocatalyst using a simple, low cost and acalable autogenic pressure method. The electrocatalyat was prepared by thermally annealing water hyacinth root containcd $\mathrm{ZnCl}_{2}$ at $700^{\circ} \mathrm{C}$ under antogenic preseure conditions. The phase of the catalyst was the minture of carbon and metal oxidc. In addition, rough surface morphology and high porocity were clearly obecrved uxing scanning electron microacope. The aynthesized catalyat was then determined the ORR performance by cyclic voltammetry (CV) and lincar swecp voltammetry (LSV) techniques under $\mathrm{O}_{2}$ saturated KOH solution. The ORR performance increased as the catalyst loading was increased and the optimum catalyst loading was found to be $1.5 \mathrm{mg} / \mathrm{cm}^{2}$ which gencrated the Eooss and Ev2 value of $0.93 \mathrm{~V}$ and $0.80 \mathrm{~V}$ va. RHE, respectively. Furthermore, the Ev/2 value of the syathesized catalyst was 230 and $130 \mathrm{mV}$ greater than the eatalyst syntheaized without $\mathrm{ZnClz}$ and commercial earbon (VXC-72R). ORR darability atudy suggested that the prepared catalyat was durable to operate ORR for 5000 cycles in allealine media. Theac results auggeated that the autogenic preasure conditions would be a promixing technique to propare highly active and durable biomass derived ORR electrocatalyat.
\end{abstract}

\section{Introduction}

Alkaline electrolyte fuel cells (AEFCs) are an highly efficient electrochemical devices that convert chemical fuel of hydrogen $\left(\mathrm{H}_{2}\right)$ and oxygen $\left(\mathrm{O}_{2}\right)$ directly into electrical energy with absolutely environmental friendliness, because only water and heat are generated as by-products [1]. The main component responsible for the performance and durability of AEFC technology is membrane electrode assembly (MEA), which comprises of an alkaline electrolyte membrane sandwiched between anode and cathode catalyst layers [1].

In $\mathrm{AEFC}, \mathrm{H}_{2}$ is fed into the anode electrode and undergoes electrochemical hydrogen oxidation reaction (HOR) by consuming hydroxide ions ( $\mathrm{OH}^{-}$) of an electrolyte, generating electrons and water as by product. $\mathrm{On}$ the other hand, $\mathrm{O}_{2}$ supplied to the cathode electrode electrochemically performs oxygen reduction reaction
(ORR) by gaining electrons in the presence of water producing $\mathrm{OH}$ ion [1].

Thermodynamically, the performance of a single AEFC cell must be constant at a potential of $1.23 \mathrm{~V}$ [1]. However, a practical single AEFC cell generates potential less than $1.23 \mathrm{~V}$ owing to three overpotential losses which are activation, ohmic and mass transport overpotentials [1]. Activation overpotential is mainly a result of the sluggish kinetic of the electrochemical HOR and ORR at the anode and cathode electrodes and it represents the main major losses of AEFC [1]. Electrochemical HOR is minimal overpotential losses (less than $20 \mathrm{mV}$ ) during fuel cell operation. On the other hand, electrochemical ORR exhibits large overpotential typically between 300 and $600 \mathrm{mV}$ [2]. The high value of cathodic ORR overpotential strongly results in lowering the overall efficiency of the AEFCs.

In order to decrease the overpotential of the ORR, substantial amount of catalysts is need to boost up ORR

\footnotetext{
Corresponding author: leriangralk lo alscioc.lmamb.ac.th
} 
performance in alkaline media. So far, the most highly active ORR catalyst is the precious platinum nanoparticle supported on carbon (Pt/C) [2]. However, this catalyst has a number of disadvantages, such as high cost, poor durability, susceptibility to gas poisoning and less abundance. These drawbacks are the major limitations to the successful commercialization of AEFCs technology [2]. Thus, a novel high-performance ORR cathode catalyst is essential to subsidize cost and enhance the AEFC performance and durability [3-6].

Recently, researcher succeeded in lowering the value of ORR overpotential by careful design atomic Pt. As a result, the Pt content significantly reduced from 2.0 $\mathrm{mg} / \mathrm{cm}^{2}$ to $0.134 \mathrm{mg} / \mathrm{cm}^{2}$ in fuel cell [6]. Further diminishing Pt content, nevertheless, lead to declining the $\mathrm{Pt}$ electrocatalyst durability [6]. In addition, the $\mathrm{Pt}$ price is contimuously increasing due to less abundant $\mathrm{Pt}$ resource and high Pt demand from other applications [6]. For this reason, development of highly active, durable non-precious Pt-free ORR electrocatalyst is highly desirable to push the commercialization of AEFCs technology.

Currently, introduction of heteroatoms (c.g., nitrogen, boron, phosphorus, sulfur) into earbon framework are highly promising candidates to replace $\mathrm{Pt}$ catalyst due to their low cost, tunable surface chemistry, and facile electron transfer mobility [7]. Among heteroatoms dopants, nitrogen (N) that is similar size and a bit higher eleetronegativity value than earbon, has been the most widely investigated as the efficient dopant to catalyse ORR [7].

Substitution of nitrogen atom into carbon framework (N-C) induces the charge of carbon atoms next to the doped nitrogen atom to be a slightly positive [8]. The positive charge of carbon atoms results in an active site for the diatomic oxygen molecule adsorption which drastically diminish ORR overpotential value [8]. In this regards, various types of independent $\mathrm{N}-\mathrm{C}$ catalysts have been studied as a possible replacement for Pt including graphene, CNTs, mesoporous carbon and nanoparticle carbon [7].

An excelleat example of N-C electrocatalyst has been described by Gong of al. [9] The nitrogen-doped vertically aligned carbon nanotubes (VA-NCNTs) electrocatalyst was prepared by thermal annealling of iron (II) phthalocyanine under $\mathrm{NH}$, atmosphere [9]. The electrochemical ORR performance of VA-NCNT investigated by linear sweep voltammogam was superior to the noble Pu'C catalyst. In addition, the VA-NCNTs eatalyst was much more durable and stable to the $\mathrm{CO}$ poisoning and the methanol crossover as compared to the precious $\mathrm{Pt} / \mathrm{C}$ electrocatalyst [9]. Despite the outstanding ORR electrocatalytic activity and durability of N-CNT catalysts, the fabrication process is relatively complicate, high cost, low yield and difficult to scale up. Moreover, the precursor is also expensive. For this reason, mumerous efforts have been devoted to develop a simple, cost effective and scalable process to synthesize N-C electrocatalyst.

Biomass, natural abundant, cost effective, renewable resources, has been a promising raw material for fabricating the highly active nitrogen doped porous carbon nanostructure electrocatalyst. Water hyacinth is nitrogen-rich biomass because it contains several types of amino acid and it can absorb the nitrogen compound in the water reservoir [10].

Liu et al. [10] converted water hyacinth into N-C electrocatalyst by thermally annealing the dried water hyacinth mixed $\mathrm{ZnCl}_{2}$ at $600-800^{\circ} \mathrm{C}$ under $\mathrm{N}_{2}$ atmosphere. The electrochemical ORR catalytic activity of samples was then investigated in $\mathrm{O}_{2}$-saturated $0.1 \mathrm{M}$ $\mathrm{KOH}$ electrolyte solution. The catalyst prepared at $700^{\circ} \mathrm{C}$ exhibited the best ORR performance. In addition, the ORR performance of the water hyacinth derived catalyst synthesized at $700^{\circ} \mathrm{C}$ was comparable to the precious Pt/C electrocatalyst. On the other hand, the prepared electrocatalyat was more durable and much more stable to the poison methanol than the precious Pt/C [10].

Wang et al. [11] succeeded in preparing highly active and durable N-C electrocatalyst derived from pomelo peel biomass. The highly porous electrocatalyst was firstly prepared by immersing the dried pomelo peel into the saturated hypersaline containing $\mathrm{NaCl}, \mathrm{ZnCl}_{2}$ and $\mathrm{FeCl}$ solution. The hypersaline treated samples were accordingly pyrolyzed under ammonia atmosphere. The ORR electrocatalytic activity of the prepared catalyst was $30 \mathrm{mV}$ more active than the state-of-the-art PuC catalyst. In addition, the hypersaline treated catalyst exhibited higher stability and more tolerate to methanol crossover as compared to the noble Pt/C catalyst [11].

Furthermore, other biomass waste including coconut shell, bagasse, soybean have also been converted into ORR non-precious electrocatalyst by calcination of the biomass precursor contained activating agent at high temperature under inert and/or ammonia atmosphere [1214]. According to the preparation procedure of converting biomass into N-C electrocatalyst, inert gas and/or ammonia atmosphere are essentially required. Heat treatment biomass under inert atmosphere may result in incomplete decomposition carbonaceous compounds leading to high ORR overpotential

In this report, we aimed to convert nitrogen rich water hyacinth biomass into the non-precious ORR electrocatalyst under alkaline condition. The water hyacinth derived catalyst with high porosity was thermally synthesized using autogenic pressure method at high temperature without using any inert gas and ammonia atmosphere. The parameters affected ORR activity of the prepared catalyst under alkaline media were measured using rotating disk electrode (RDE) analysis. The obtained ORR activity was compared to that of the ORR performance of the noble Pt catalyst. The novelty of this research was the synthesis and electrochemical ORR performance under alkaline media of the water hyacinth catalyst synthesized using an autogenic pressure condition which has not been reported to date. Compared to catalyst prepared by reference [10], the catalyst in this study was prepared from water byacinth root without using any inert gas at high temperature. while, the catalyst obtained in reference [10] derived from water hyacinth trunk and thermally annealed in presence of inert atmosphere. 


\section{Materials and methods}

\subsection{Preparation of electrocatalysts}

The protein rich water hyacinth root was perfectly cleaned using large quantity of DI water and dried at $80^{\circ} \mathrm{C}$ overnight. The dried sample was then grinded into small pieces and then the ground sample was physically mixed with $\mathrm{ZnCl}_{2}$. The mixture powder was transferred into the high pressure cell and close tightly with the caps. The cell was then thermally heated at the temperature of $700^{\circ} \mathrm{C}$ under ambient atmosphere. The activating agent contained in heated sample was eliminated by dissolving the heated sample in $0.5 \mathrm{M}$ $\mathrm{H}_{2} \mathrm{SO}_{4}$ solution for $8 \mathrm{hr}$ at $80^{\circ} \mathrm{C}$. The black solid powder sample was obtained after being washed and dried at $80^{\circ} \mathrm{C}$. To compare the effect of porosity, water hyacinth was prepared the same procedure except $\mathrm{ZnCl}_{2}$ was not included. The samples prepared with $\mathrm{ZnCl}_{2}$ and without $\mathrm{ZnCl}_{2}$ were named WHCR- $\mathrm{Zn}$ and WHCR, respectively.

\subsection{Physical characterizations}

Field-emission scanning electron microscope (FE-SEM, Hitachi S-4800II) with an accelerated voltage of $3 \mathrm{kV}$ was employed to investigated the morphology of samples. Please note that the sample was coated with osmium before SEM analysis. The cryatal structure of samples was investigated using powder X-ray diffraction (XRD, PANanalytical-Empyrean) using $\mathrm{K} e$ radiation and generation voltage of $40 \mathrm{kV}$. Thermal stability of sample was evaluated using thermal gravimetric analysis (TGA).

\subsection{Electrochemical characterizations}

Catalyst ink was prepared by ultrasonic mixing catalyst powder, DI-water, 5\% Nafion and Isopropyl alcohol followed the literature [15]. A working electrode was prepared by dropping eatalyst ink on the surface of a clean glassy carbon and left it dry under ambient conditions. The catalyst loading on the glassy carbon electrode was $0.5 \mathrm{mg} / \mathrm{cm}^{2}$ while the amount of reference sample which is $\mathrm{Pt} / \mathrm{C}$ was $60 \mu \mathrm{g} / \mathrm{cm}^{2}$. Working electrode was then assembled into an electrochemical cell where Pt wire used as a counter electrode and saturated calomel electrode (SCE) used as reference electrode were also connected. The ORR catalytic activity was evaluated under $\mathrm{O}_{2}$-saturated $0.1 \mathrm{M} \mathrm{KOH}$ solution using rotating disk electrode $(\mathrm{RDE})$ and cyclic voltametry technique (Pine instrument) with scan rate of $10 \mathrm{mV} / \mathrm{s}$. RDE and CV experiments were repeatedly investigated at least 3 times.

\section{Results and discussion}

Fig. 1a represented TGA thermogram of root, leaves and trunk of water hyacinth sample under $\mathrm{N}_{2}$ atmosphere. It was found that all samples exhibited three stages of weight loss i.e. dehydration $\left(100^{\circ} \mathrm{C}\right)$, bemicellulose decomposition $\left(290^{\circ} \mathrm{C}\right)$ and cellulose decomposition $\left(370^{\circ} \mathrm{C}\right)$.
The main composition of biomass was hemicellulose, cellulose and lignin. The molecular structure of cellulose and hemicellulose was a simple sugar monomer which easily decomposed into light organic compound at a temperature lower than $450^{\circ} \mathrm{C}$. Lignin was a high molecular weight hydrophobic polymer comprising of various functional group containing aromatic structure of carbon. In the heat treatment process, lignin underwent decomposing slowly in a whole range of temperature leaving condensed aromatic carbon with reduced functional groups. The residue at temperature of $700^{\circ} \mathrm{C}$ of root, leaves and trunk of water hyacinth was $55 \%, 25 \%$ and $22 \%$, respectively. The amount of residue obtained from root was twice times larger than leaves and trunk. The high residue value suggested high carbon conversion yield. Thus, this research would like to utilize water hyacinth root to fabricate the ORR electrocatalyst. This was done by thermally heating the ground water hyacinth root mixed $\mathrm{ZnCl}_{2}$ under autogenic pressure conditions. $\mathrm{ZnCl}_{2}$ was used as activating agent to generate pores and it was chemically removed using 0.5 $\mathrm{M} \mathrm{H}_{2} \mathrm{SO}_{4}$. The obtained catalyst was then investigated phase analysis using XRD technique and the result was displayed in Fig. 1b. The phase of catalyst was the mixture of carbon and metal oxides. The formation of carbon was broadly observed at $2 \theta$ of 25 and 43 degree, corresponding to graphitic $\mathrm{C}(002)$ and $\mathrm{C}(100)$ turbostatic carbon structure [15]. In addition, various types of metal oxides, such as $\mathrm{SiO}_{2}, \mathrm{MgO}, \mathrm{CaO}$, were also detected in the XRD pattern. The observed several types of metal oxides in the catalyst was due to the accumulation of inorganic compounds by water hyacinth root, leading to metal oxide after pyrolysis. Fig. 1c and 1d illustrated the morphology of catalyst visualized by SEM technique. Low magnification SEM image revealed the rod and particles morphologies (Fig 1c).
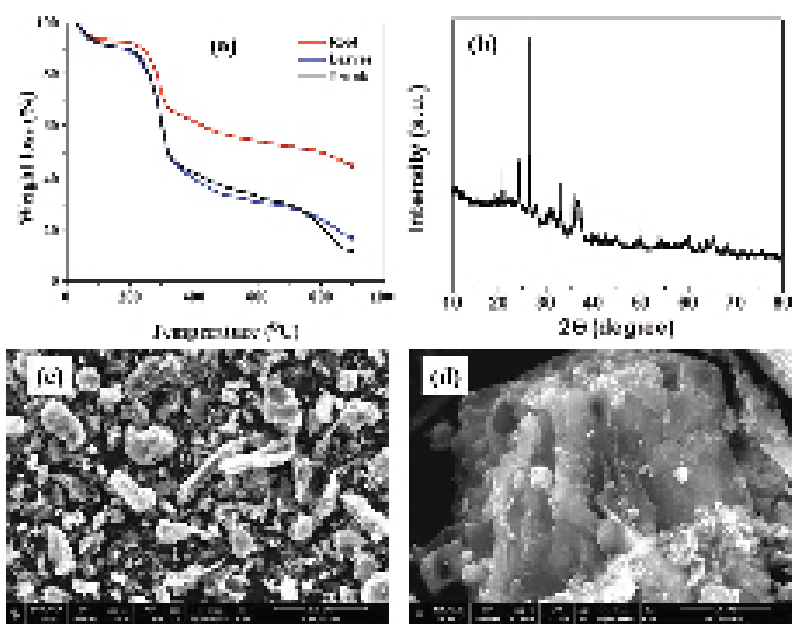

Fig. 1. (a) TGA thermogram of root, leave and trunlk of water hyacinth under $\mathrm{N}_{2}$ atmocphere, (b) XRD pattern of water hyacinth root heated at $700^{\circ} \mathrm{C}$ for $1 \mathrm{~h}$ under atogenic preasure conditions, SEM images of WHCR-Zn catalyst (c) low magnification and (d) high magnification.

In addition, uneven surface and porous structure were observed in the high magnification SEM image (Fig. 1d). Furthermore, the elemental nitrogen content was also 
verified using SEM elemental mapping analysis. The nitrogen content incorporated into catalyst was 3.04 atomic\%. It was reported that nitrogen was able to effectively bind to carbon with three configurations: pyridinic-like, pyrolic-like and graphitic-like [15]. However, the precisely $\mathrm{ORR}$ active site has so far still debated. But pyridinic and graphitic were intensively accepted as the major ORR active sites. It should be highlighted that heat treatment of water hyacinth root contained $\mathrm{ZnCl}$ at $700^{\circ} \mathrm{C}$ under autogenic pressure conditions resulted in the decomposition of moisture, cellulose and hemi-cellulose, leading to the formation of carbon. On the other hand, $\mathrm{ZnCl}$ was buried in the surface of sample and the embedded $\mathrm{ZnCl}_{2}$ was completely eliminated by hot acid solution, leaving porous structure. In addition, nitrogen atom was efficiently doped into carbon framework at this pyrolysis conditions.

Next, the WCHR- $\mathrm{Zn}$ catalyst was electrochemically evaluated the ORR catalytic activity in an $\mathrm{O}_{\mathrm{r}}$-saturated $\mathrm{KOH}$ solution at scan rate of $10 \mathrm{mV} / \mathrm{s}$ using cyclic voltammetry (CV) and linear sweep voltammetry (LSV) techniques. CV voltammogram of various eatalyst contents were thermodynamically aetive for catalyzing ORR in alkaline media (Fig. 2a). To estimate the ORR kinetic, catalysts were conducted rotating disk electrode $(R D E)$ experiments under alkaline condition at a rotation speed of $1600 \mathrm{rpm}$ and the results were showed in Fig. $2 \mathrm{~b}$.
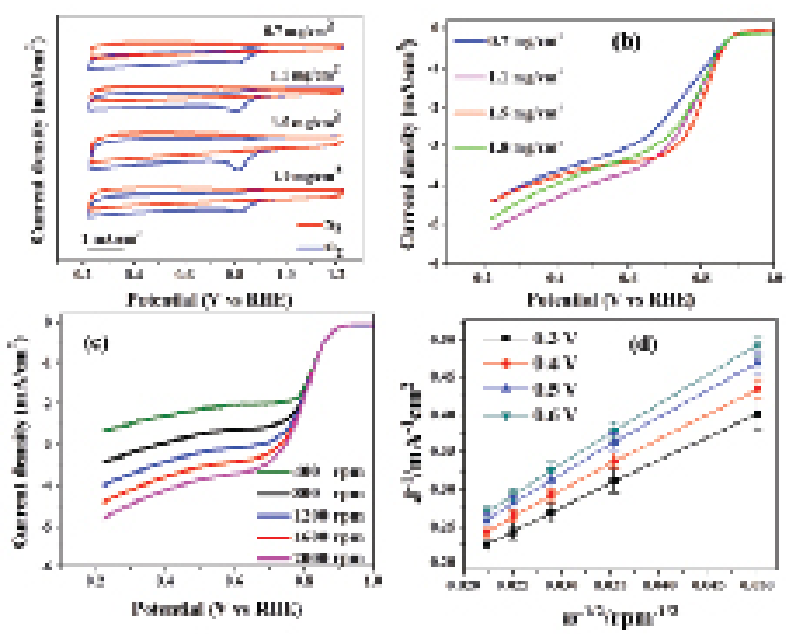

Fig. 2. ORR polarization curves of various contents of WHCR$\mathrm{Zn}_{\mathrm{n}}$ clectrocatalyat by (a) cyclic voltammogram and (b) lincar swecp voltammogram (LSV) at rotating speed of $1600 \mathrm{rpm}$ (c) ORR polarization curve at different rotation apeed of WHCR$\mathrm{Zn}$ catalyet with content of $1.5 \mathrm{mg} / \mathrm{cm}^{2}$ and its corrcaponding Koutcelsy-Levich plots (d) in $\mathrm{O}_{2}$-saturated $0.1 \mathrm{M} \mathrm{KOH}$ solution.

The LSV polarization curve (Fig. 2b) indicated onset potential $\left(E_{\text {ousct }}\right)$, half-wave potential $\left(E_{1 / 2}\right)$ and steady state current diffusion. $E_{\text {ane }}$ value increased as catalyst content was increased. This was mainly due to the increment of the number of active site where more oxygen molecules were able to adsorb and consequently facilitating the $O R R$ in alkaline media. On the other hand, large amount of catalyst on RDE electrode also led to large value of $E_{1 / 2}$. However, the more content of catalyst was loaded on an electrode resulted in thick catalyst layer which hindered the accessibility of an oxygen molecule to be electrochemical reduction reaction into water. Thus, the optinmm loading of WHCR$\mathrm{Zn}$ catalyst was $1.5 \mathrm{mg} / \mathrm{cm}^{2}$. Fig $2 \mathrm{c}$ illustrated the LSV plot at rotation speed of $400-2000 \mathrm{rpm}$ of the optimum WHCR- $\mathrm{Zn}$ catalyst in an $\mathrm{O}_{2}$-saturated $\mathrm{KOH}$ solution. It was found that current density increased as the rotation speed was increased due to the shortening flux-diffusion. Fig. 2d shows the Koutecky-Levich (K-L) plots derived from the LSV plot (Fig. 2c) and this plot indicated good linearity and parallelism over all the potential range, suggesting the first order reaction kinetics for the ORR [16]. The electron transfer number of the synthesized water hyacinth root catalyst calculated at $0.5 \mathrm{~V}$ was found to be 3.6, indicating the catalyst possessed a direct four electron transfer. Fig. 3a compared CV voltammogram of WHCR-Zn catalyst with that of WHCR, commercial carbon (VXC-72R) and the noble $\mathrm{Pt} / \mathrm{C}$ electrocatalysts in alkaline solution. The $\mathrm{E}_{\mathrm{ases}}$ of WHCR- $\mathrm{Zn}$ catalyst was clearly more positive than WHCR and VXC-72R catalysts, suggesting more thermodynamically active than WHCR and VXC-72R catalysts. However, $\mathrm{E}_{\text {eart }}$ of WHCR-Zn catalyst was more negative as compared to the expensive $\mathrm{Pt} / \mathrm{C}$ catalyst. In order to visualize ORR kinetic reaction of various catalysts, LSV experiment was performed in
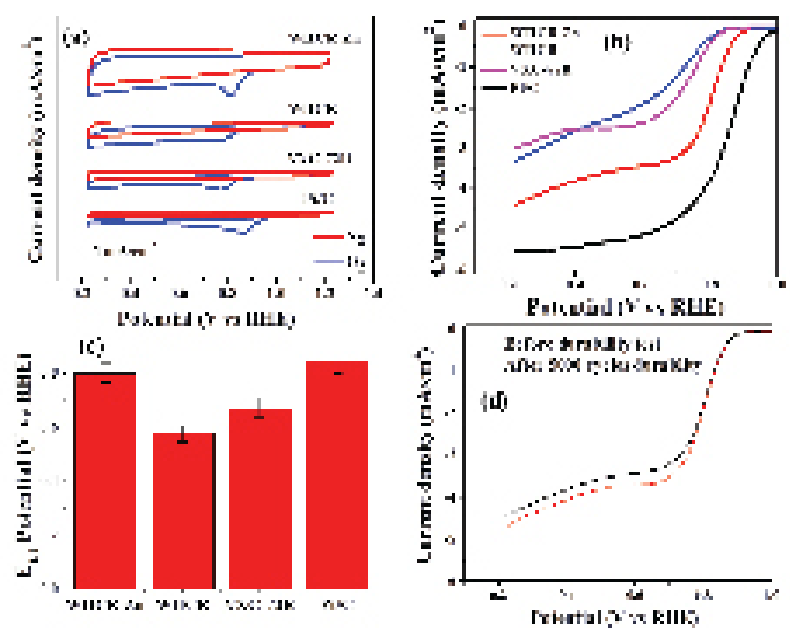

Fig. 3. ORR polarization curves of WHCR $-\mathrm{Z}_{\mathrm{n}}$, WHCR, commercial carbon (VXC-72R) and the noble PuC electrocatalyats by (a) cyclic voltammogram and (b) lincar swcap voltammogram (LSV) at $1600 \mathrm{rpm}$ (c) its corresponding EV/2 potcatial and (d) accelerated durability test for 5000 cycles of WHCR-Zn electrocatalyat in $\mathrm{O}_{2}$-sanurated $0.1 \mathrm{M} \mathrm{KOH}$ solution.

$\mathrm{O}_{\mathrm{r}}$-saturated $\mathrm{KOH}$ solution at rotating speed of $1600 \mathrm{mpm}$ and a result was depicted in Fig. 3b and Fig. 3c. The $E_{\text {anes }}$ value of WHCR-Zn, WHCR, VXC-72R and PU/C catalysts was $0.93,0.86,0.88$ and $1.0 \mathrm{~V}$ vs. RHE, respectively. The WHCR-Zn catalyst exhibited 170 and $150 \mathrm{mV}$ more positive $\mathrm{E}_{\text {ouser }}$ value than that of the WHCR, VXC-72R catalysts. The more positive $\mathrm{E}_{\text {ousct }}$ value indicated less overpotential to catalyze $O R R$ in alkaline media. On the other hand, the value of $\mathrm{E}_{1 / 2}$ of 
WHCR- $\mathrm{Zn}$, WHCR, VXC-72R and Pt/C catalysts was $0.80,0.57,0.67$ and $0.84 \mathrm{~V}$ vs. RHE. The $\mathrm{E}_{/ 2}$ value of WHCR-Zn catalyst was $230,130 \mathrm{mV}$ greater than that of WHCR and VXC-72R catalysts. The higher Eecest and $E_{1 / 2}$ value of WHCR-Zn catalyst over WHCR was mainly attributed to the higher porosity as well as high surface area of WHCR-Zn catalyst against WHCR. The higher porosity and surface area resulted in more catalyst active site, yielding excellent ORR performance. On the other hand, the greater Easer and $\mathrm{E}_{1 / 2}$ value of WHCR-Zn catalyst against the commercial VXC- $72 R$ was a result of the presence of $\mathrm{N}$ incorporated into the carbon framework as well as the formation of metal oxide which generated the ORR active site, facilitating excellent $O R R$ catalytic activity toward VXC-72R. However, the $\mathrm{E}_{\text {seast }}$ and $E_{1 / 2}$ value of WHCR-Zn catalyat were 70 and $40 \mathrm{mV}$ lower than that of the state of the art Pv/C eatalyst. In order to determine the effectiveness of the electrocatalyst preparation method, we compared the $E_{2 / 2}$ of WHCR-Zn catalyst with that of the biomass derived electrocatalyst (coconut shell [12], soybean [13], bagasse [14]) which was prepared by thermally annealing at high temperature under inert gas and ammonia atmosphere. It was found that the $E_{1 / 2}$ value of electrocatalyst derived from coconut shell, soybean and bagasse was found to be $0.78,0.74$ and $0.76 \mathrm{~V}$ vs RHE, respectively [12-14]. The WHCR-Zn electrocatalyst exhibited outperform ORR performance relative to biomass electrocatalyst synthesized by conventional method. These results suggested that the novel autogenetic pressure method was effective to prepare highly active biomass derived ORR electrocatalyst. Fig. 3d represented the accelerated durability test for 5000 cycles of WHCR-Zn catalyst in $\mathrm{O}_{2}$-saturated $\mathrm{KOH}$ solution at scan rate of $50 \mathrm{mV} / \mathrm{s}$. The $\mathrm{E}_{1 / 2}$ value of WHCR-Zn catalyst before and after 5000 cycling durability test was negative shift with a value of $10 \mathrm{mV}$. It was reported that the $\mathrm{E}_{1 / 2}$ value of $\mathrm{Pt} / \mathrm{C}$ catalyst after 5000 cycling durability test is $50 \mathrm{mV}$ negative shift [16]. These results suggested the surface of WHCR- $\mathrm{Zn}$ catalyst was maintained without degradation after 5000 cycling test. However, the drastic degradation of the precious $\mathrm{Pt} / \mathrm{C}$ catalyst was mainly due to the aggregation of Pt nanoparticle on the surface of carbon support leading to lower the active area. Furthermore, Pt dissolution and carbon oxidation during accelerated durability test were also contributed to the Pt/C degradation [16]. The high ORR catalytic performance as excelleat as durability of biomass derive electrocatalyst could generate a promising solution to alleviate the eaviroamental issue as well as global warming.

\section{Conclusion}

We demonstrated the conversion of water hyacinth biomass into ORR electrocatalyst by thermally heating the sample contained $\mathrm{ZnCl}_{2}$ under an antogenic pressure method. The prepared sample exhibited high porosity as well as high $\mathrm{N}$ content incorporated in to carbon and metal oxide structure. The greater porosity and $\mathrm{N}$ functional group resulted in high ORR catalytic activity in alkaline solution. The optimum catalyst loading was found to be $1.5 \mathrm{mg} / \mathrm{cm}^{2}$. In comparison to the catalyst prepared without $\mathrm{ZnCl}_{2}$ and commercial carbon (VXC$72 R$ ), the synthesized catalyst exhibited excellent ORR performance in alkaline media. In addition, the prepared catalyst showed highly stable cycling test for 5000 cycles with negligible $O R R$ activity loss.

This rescarch was funded by Faculty of Science, Energy and Environment, King Mongkut's University of Technology North Banglook (Rayong campus). Contract no. SciEE-001/62

\section{Reference}

1. M. C. Williams, Fuel Cell Handbook (Fifh Edition), EG\&G Services Parsons, Inc. 352 (2000)

2. J. Zhang, PEM fivel cell electrocatalysts and catalyst layers: findamentals and applications, Springer (2008).

3. C.W.B. Bezerra, L. Zhang, K. Lee, H. Liu, E.P. Marques, H. Wang, et al., Electrochim. Acta. 53, 4937 (2008)

4. M. Shao, Q. Chang, J. P. Dodelet, R. Chenitz, Chem. Rev. 116, 3594 (2016)

5. A. A. Gewirth, J. A. Varnell, A. M DiAscro, Chem. Rev. 118, 2313 (2018)

6. L. Zhang, D. P. Wilkinson, Y. Liu, J. Zhang, Electrochim Acta. 262, 326 (2018)

7. L. Dai, Y. Xue, L. Qu, H. J. Choi, J. B. Chem Rev. 115,4823 (2015)

8. X. Liu, L. Dai, Nat. Rev. Mater. 1, 16064 (2016)

9. K. Gong, F. Du, Z. Xia, M. Durstock, L. Dai, Science. 323, 760 (2009)

10. X. Liu, Y. Zhou, W. Zhou, L. Li, S. Huang, S. Chen, Nanoscale. 7, 6136 (2015)

11. N. Wang, T. Li, Y. Song, J. Liu and F. Wang, Carbon. 136, 692 (2018)

12. M. Borghei, N. Laocharoen, E. Kibena-Poldsepp, L. S. Johansson, J. Campbell, E. Kauppinen, K. Tammeveski, O. J. Rojas, Appl Catal B: Environ. 204, 394 (2017)

13. W. Yuan, A. Xie, S. Li, F. Huang, P. Zhang, Y. Shen, Energy. 115, 397 (2016)

14. G. Lin, $\mathbb{R}$ Ma, Y Zhou, Q. Liu, X. Dong and J. Wang, Electrochim. Acta. 261, 49 (2018)

15. J. Sanetuntikul, T. Hang, S. Shannugam, Chem. Commun. 50, 9473 (2014)

16. J. Sanetuntikul, S. Shanmugam, Nanoseale. 7(17), 7644 (2015). 